\title{
Decoupling analysis of the carbon emissions' change and the economic growth in Jiangxi's agricultural sector
}

\author{
Jianfeng Chen ${ }^{1,2}$, Junsong $\mathrm{Jia}^{1,2}$, Chunyan $\mathrm{Liu}^{1,2, *}$ and Duanqian $\mathrm{Mao}^{1,2}$ \\ ${ }^{1}$ School of Geography and Environment, Jiangxi Normal University, Nanchang, Jiangxi, 330022, China \\ ${ }^{2}$ Key Laboratory of Poyang Lake Wetland and Watershed Research, Ministry of Education, Jiangxi Normal University, Nanchang, \\ Jiangxi, 330022, China
}

\begin{abstract}
Taking Jiangxi's agricultural sector as an example, we first computed the carbon emissions of Jiangxi's agricultural sector during 2005-2018 in this paper, and then used the Tapio decoupling model to explore the decoupling status between the carbon emissions' change and the economic growth. The results showed that: the carbon emissions of Jiangxi's agriculture, first, increased from $236.98 \times 10^{4} \mathrm{t}$ in 2005 to $274.00 \times 10^{4} \mathrm{t}$ in 2015 , and then decreased from $270.74 \times 10^{4} \mathrm{t}$ in 2016 to $247.95 \times 10^{4} \mathrm{t}$ in 2018 . The decoupling relationship between the carbon emissions' change and the economic growth mainly expressed as weak decoupling during 2005-2015 and strong decoupling during 2015-2018. The reason was that Jiangxi's economy is no longer developing in an extensive way, but is shifting to a low-carbon development pattern. Namely, the carbon emissions from chemical fertilizer and pesticide were the most important part of agricultural carbon emissions. Moreover, this part's emissions showed a significant downward trend along with the update of agriculture technology and the improvement of production efficiency. Thus, some particular suggestions to reduce the agricultural carbon emissions of Jiangxi were put forward.
\end{abstract}

\section{Introduction}

The climate change has become an important global issue that is related to energy, economics, environment, technology and agriculture. Therefore, more and more countries and scholars pay attention to this issue. If we don't take further actions to manage this problem or reduce the corresponding carbon emissions, this trouble will bring immeasurable harm to the economic and social development of countries all over the world.

Particularly, agricultural carbon emission is one of the most important parts of carbon emissions, so the impact of agricultural carbon emissions on climate change cannot be ignored. Jiangxi is one of the main grain-producing areas in China, in which agriculture occupies an important position in economic development.

Therefore, it is of great significance to reduce agricultural carbon emissions for establishing a modern agricultural system and promoting sustainable agricultural development in Jiangxi Province.

Some scholars have conducted the related studies on agricultural carbon emissions. For instance, Min et al. [1] calculated the corresponding emissions of China's crop and animal husbandry industries by using the carbon emission coefficient method. Han et al. [2] used the logarithmic mean Divisia index (LMDI) to decompose the driving factors of China's agriculture carbon emissions. Li et al. [3] used the environmental Kuznets curve (EKC) to test the relationship between the agricultural carbon emissions and the per-capita GDP of China. Cao et al. [4] compared the regional differences of carbon emissions in Shandong and used the Tapio decoupling model to calculate and analyze the decoupling elasticity of agricultural carbon emissions.

However, most scholars prefer to measure agricultural carbon emissions from the perspective of countries or developed regions, and few of them pay attention to the underdeveloped regions or areas such as Jiangxi, Qinghai and Xizang.

Thus, taking Jiangxi's agricultural sector as a case, we used the Tapio decoupling model to explore the decoupling status between the carbon emissions' change and the economic growth, which can make up this gap of the existing research to some extent.

\section{Data and methods}

\subsection{Data sources}

The data, including the related economic output and various items of Jiangxi's agricultural sector, are all derived from the Jiangxi Statistical Yearbook (2005-2018).

What's more, agriculture particularly refers to crop production in this paper. The year 2005 is used as the base year and all other year's data are calculated by 2005 constant price.

\footnotetext{
* Corresponding author: 1cy200505@163.com
} 


\subsection{Methods}

\subsubsection{Computing method of carbon emission and carbon intensity}

By reference to the previous research, the carbon emission's coefficient method was used to calculate the agricultural carbon emissions of Jiangxi on the basis of the actual situation of this province's agricultural development, which was listed as the following equation (1):

$$
E=\sum E_{i}=\sum T_{i} \times \delta_{i}
$$

Where: $E$ denotes the total carbon emissions of agriculture; $i$ denotes the carbon source type; $T_{i}$ denotes the amount of $i$ carbon source; $\delta_{i}$ denotes the carbon emission's coefficient of $i$ carbon source, which was listed as the following Table 1 .

Table 1. Carbon emission's coefficient and its reference source

\begin{tabular}{|c|c|c|c|}
\hline $\begin{array}{l}\text { Carbon } \\
\text { source }\end{array}$ & $\begin{array}{c}\text { Carbon } \\
\text { emission's } \\
\text { coefficient }\end{array}$ & Unit & $\begin{array}{c}\text { Reference } \\
\text { source }\end{array}$ \\
\hline $\begin{array}{l}\text { Chemical } \\
\text { fertilizer }\end{array}$ & 0.8956 & $\mathrm{kgC} / \mathrm{kg}$ & $\begin{array}{c}\text { Duan et al. } \\
{[5]}\end{array}$ \\
\hline $\begin{array}{l}\text { Agricultural } \\
\text { film }\end{array}$ & 5.18 & $\mathrm{kgC} / \mathrm{kg}$ & $\begin{array}{c}\text { Duan et al. } \\
{[5]}\end{array}$ \\
\hline Pesticide & 4.9341 & $\mathrm{kgC} / \mathrm{kg}$ & $\begin{array}{c}\text { Duan et al. } \\
\text { [5] }\end{array}$ \\
\hline $\begin{array}{c}\text { Agricultural } \\
\text { diesel }\end{array}$ & 0.5927 & $\mathrm{kgC} / \mathrm{kg}$ & IPCC \\
\hline Irrigation & 266.48 & $\mathrm{kgC} / \mathrm{hm}^{2}$ & $\begin{array}{c}\text { Duan et al. } \\
\text { [5] }\end{array}$ \\
\hline Land plowing & 312.6 & $\mathrm{kgC} / \mathrm{km}^{2}$ & $\begin{array}{c}\text { Wu et al. } \\
{[6]}\end{array}$ \\
\hline
\end{tabular}

Moreover, the formula for calculating agricultural carbon intensity was listed as the following equation (2):

$$
A=E / S
$$

Where: $A$ denotes the carbon intensity; $S$ denotes the total cultivated area.

\subsubsection{Tapio decoupling model}

Based on the Organization for Economic Co-operation and Development (OECD) decoupling model, Tapio introduced the concept of "decoupling elasticity" to construct the decoupling index, which solves the difficulty of the OECD decoupling model in the selection of the base period [7]. The Tapio decoupling model can reflect the relationship between the carbon emissions' change and the economic growth, and help to grasp the development trend of regional carbon emissions, which was listed as the following equation (3):

$$
e=\frac{\Delta C / C}{\Delta G / G}
$$

Where: $e$ denotes the decoupling elasticity between the carbon emissions' change and the economic growth of agriculture; $\Delta C$ denotes the change in agricultural carbon emissions during the research period; $C$ denotes the agricultural carbon emissions at the base period; $\Delta G$ denotes the change in gross output value of agriculture during the research period; $G$ denotes the gross output value of agriculture at the base period.

\section{Results and analysis}

\subsection{Empirical analysis of the carbon emissions in Jiangxi's agricultural sector}

As shown in Figure 1, since the Rise Strategies of Central China was proposed in 2004, the gross output value of Jiangxi's agricultural sector has grown from $510.47 \times 10^{8}$ yuan in 2005 to $903.29 \times 10^{8}$ yuan in 2018 , with an increasing amount of $392.82 \times 10^{8}$ yuan and an average annual growth rate of $4.49 \%$. This result shows that Jiangxi's agricultural development has achieved excellent status in economic effect. The reason may be that Jiangxi had attached much great importance to the industrialization and modernization of agriculture, and increased the investment in agricultural infrastructure, which improved the efficiency of agricultural production.

With the increasing of gross output value in agricultural sector, the carbon emissions of Jiangxi's agriculture, first, increased from $236.98 \times 10^{4} \mathrm{t}$ in 2005 to $274.00 \times 10^{4} \mathrm{t}$ in 2015 , with an average annual growth rate of $1.46 \%$; then it decreased from $270.74 \times 10^{4} \mathrm{t}$ in 2016 to $247.95 \times 10^{4} \mathrm{t}$ in 2018 , with an average annual change rate of $-4.3 \%$. Similarly, the carbon intensity increased from $444.7 \mathrm{~kg} / \mathrm{hm}^{2}$ in 2005 to $491.12 \mathrm{~kg} / \mathrm{hm}^{2}$ in 2015 , and then it decreased from $483.28 \mathrm{~kg} / \mathrm{hm}^{2}$ in 2016 to $446.28 \mathrm{~kg} / \mathrm{hm}^{2}$ in 2018.

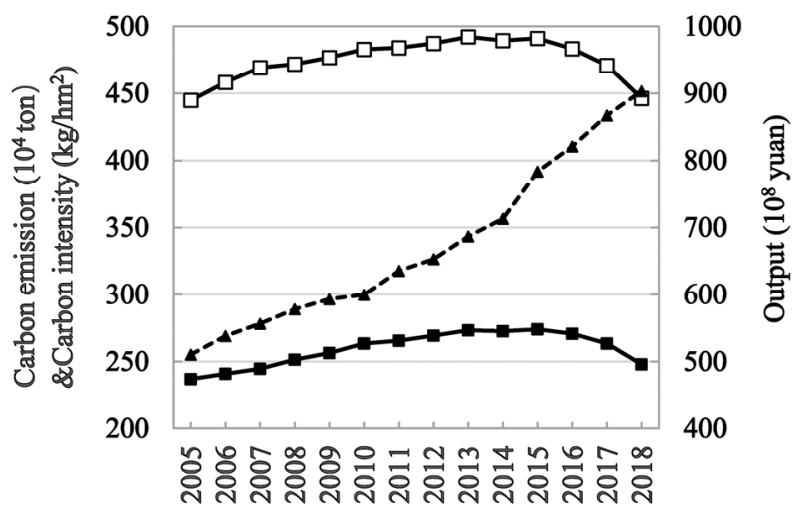

$\rightarrow-$ Carbon emission $\longrightarrow \square-$ Carbon intensity --^--O Output value

Fig. 1. Carbon emission, intensity and output

As shown in Figure 2, chemical fertilizer is the largest carbon source of agricultural carbon emissions, with an average annual proportion of $47.18 \%$ to the total of agricultural carbon emissions. Specifically, the carbon emissions of chemical fertilizer, first, increased from $115.89 \times 10^{4} \mathrm{t}$ in 2005 to $128.59 \times 10^{4} \mathrm{t}$ in 2015 , with an average annual growth rate of $1.05 \%$. Then, it decreased from $127.15 \times 10^{4} \mathrm{t}$ in 2016 to $110.33 \times 10^{4} \mathrm{t}$ in 2018 , with an average annual change rate of $-6.85 \%$.

It can be easily seen that the carbon emissions of 
chemical fertilizer had the most significant impact on the agricultural carbon emissions and the carbon intensity. However, the proportion of the chemical fertilizer's emissions showed a decreasing trend, decreased slightly from $48.90 \%$ in 2005 to $44.50 \%$ in 2018 . The reason may arise from the continuous innovation of agriculture technology and improvement of production efficiency.

The second's contributor is irrigation, with an average annual proportion of $19.79 \%$ to the total emissions. The third is pesticide, with an average annual proportion of $17.46 \%$. The following is the agricultural film (agricultural diesel), with an average annual proportion of $9.54 \%(6.02 \%)$. The last is land plowing, with an average annual proportion of $0.01 \%$.

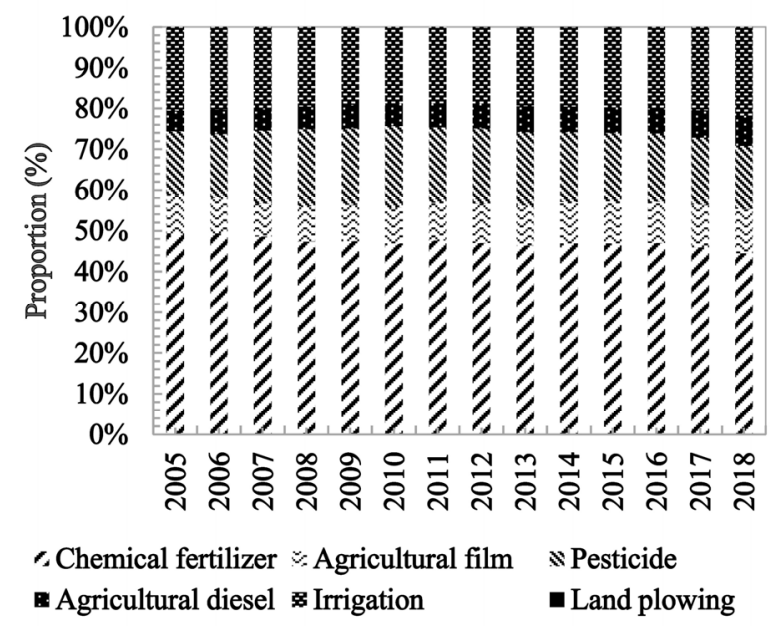

Fig. 2. The composition of carbon emission

\subsection{Decoupling elasticity results and analysis}

On the basis of the values of decoupling elasticity, we can draw a picture of the decoupling model between the carbon emissions and the economic development in agricultural sector, which is shown in Figure 3.

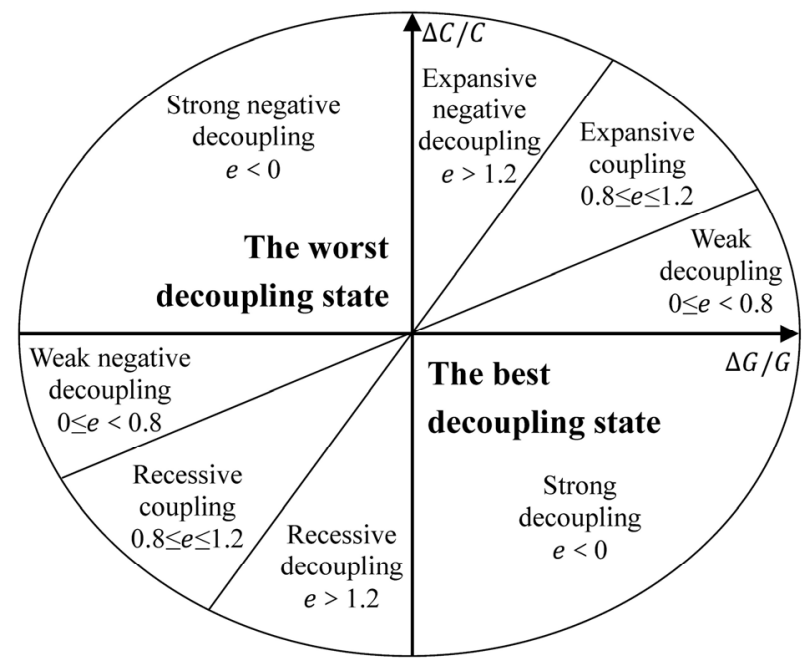

Fig. 3. Schematic diagram of decoupling states

The decoupling state can be divided into 3 categories: decoupling, coupling, negative decoupling, and then subdivided into strong decoupling, weak decoupling, recessive decoupling, expansive coupling, recessive coupling, strong negative decoupling, weak negative decoupling, and expanding negative decoupling. Among them, strong decoupling is the best decoupling state, indicating that the agriculture's output continues to increase, while the amount of carbon emissions decreasing; strong negative decoupling is the worst decoupling state, indicating that the agriculture's output is reducing, while the amount of carbon emissions is increasing.

According to the equation (3), the decoupling elasticity of carbon emissions in Jiangxi's agricultural sector during 2005-2018 were calculated as shown in Figure 4.

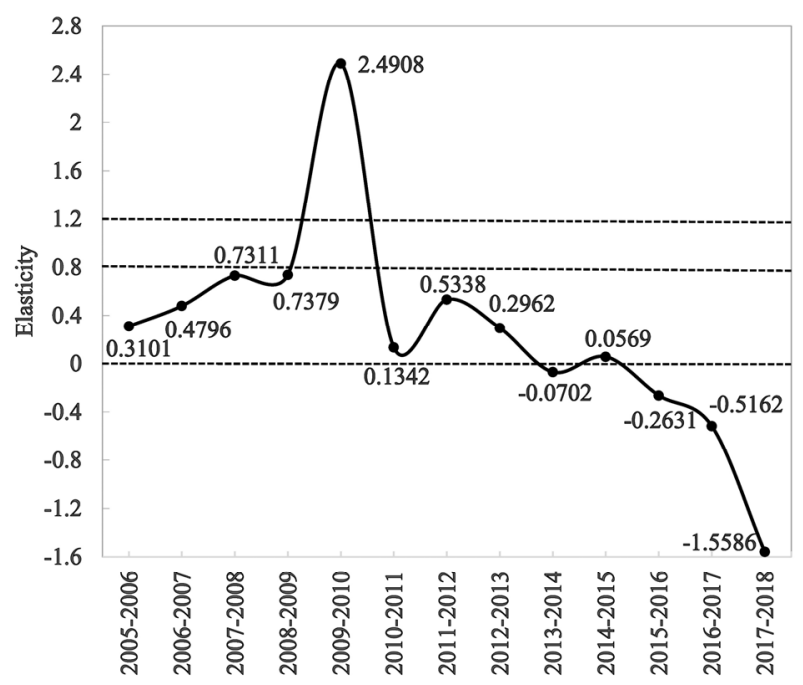

Fig. 4. Decoupling elasticity

On the whole, the decoupling relationship between the carbon emissions' change and the economic growth mainly expressed as weak decoupling and strong decoupling during 2005-2018. It means that Jiangxi's agriculture has made great achievements due to the promotion of low-carbon development.

Specifically, the decoupling relationship between the carbon emissions' change and the economic growth mainly experienced two stages. The first is the stage of weak decoupling during 2005-2015. The decoupling elasticity is 0.2923 . That is to say, economic growth was faster than the change of carbon emissions. However, it should be noteworthy that the decoupling elasticity experienced large fluctuation and expressed as expansive negative decoupling during 2009-2010. The main reason was that the proportion of carbon emissions of chemical fertilizer and pesticide reached the peak, accounting for $66.72 \%$. This might be related to the large-scale investment in order to restore economic development after 2008 financial crisis.

Besides, the second is the stage of strong decoupling during 2015-2018, the decoupling elasticity is -0.6208 . Namely, the decoupling relationship presented an ideal state between the carbon emissions' change and the economic growth. The reason might be that Jiangxi was listed in the national pilot zone for ecological conservation in 2016. This means that more attention has been paid to low-carbon development, and the input of agricultural material has been controlled effectively. 
Consequently, with the increasing of gross output in agricultural sector, the carbon emission decreased from $270.74 \times 10^{4} \mathrm{t}$ in 2016 to $247.95 \times 10^{4} \mathrm{t}$ in 2018 , with an average annual change rate of $-4.3 \%$. Especially, the carbon emission of fertilizer and pesticide has rapidly decreased from $172.64 \times 10^{4} \mathrm{t}$ in 2016 to $148.42 \times 10^{4} \mathrm{t}$ in 2018 , with an average annual change rate of $-7.28 \%$.

\section{Conclusions}

The gross output value of Jiangxi's agricultural sector has grown from $510.47 \times 10^{8}$ yuan in 2005 to $903.29 \times 10^{8}$ yuan in 2018 , with an average annual growth rate of $4.49 \%$. The carbon emissions of Jiangxi's agriculture, first, increased from $236.98 \times 10^{4} \mathrm{t}$ in 2005 to $274.00 \times 10^{4} \mathrm{t}$ in 2015 , with an average annual growth rate of $1.46 \%$. Then it decreased from $270.74 \times 10^{4} \mathrm{t}$ in 2016 to $247.95 \times 10^{4} \mathrm{t}$ in 2018 , with an average annual change rate of $-4.3 \%$. The carbon intensity increased from $444.7 \mathrm{~kg} / \mathrm{hm}^{2}$ in 2005 to $491.12 \mathrm{~kg} / \mathrm{hm}^{2}$ in 2015 , and then it decreased from 483.28 $\mathrm{kg} / \mathrm{hm}^{2}$ in 2016 to $446.28 \mathrm{~kg} / \mathrm{hm}^{2}$ in 2018 . The chemical fertilizer was the largest carbon source of agricultural carbon emissions, followed by irrigation, pesticide, agricultural film, agricultural diesel and land plowing.

What's more, the decoupling relationship between the carbon emissions' change and the economic growth experienced two stages, the first is the stage of weak decoupling during 2005-2015, and the second is the stage of strong decoupling during 2015-2018.

The results showed that Jiangxi's agriculture has made great achievements due to the promotion of low-carbon development. The reason was that with the transformation of economic development mode, the input of agricultural material such as chemical fertilizer and pesticide had obviously begun to be controlled.

However, the amount of agricultural carbon emissions is still huge. Thus, the following suggestions could be put forward to promote the low-carbon development of Jiangxi's agriculture.

First, the agriculture structure should be optimized. The agriculture structure of Jiangxi was still dominated by crop production. So, the proportion of forestry, animal husbandry and fishery should be increased appropriately, and the proportion of crop production with high consumption should be reduced.

Second, the input of agricultural material should be controlled. For instance, the chemical fertilizer and pesticide played a primary role in the carbon emissions and decoupling status. Therefore, it is important to control the input of agricultural material such as configuring chemical fertilizer according to the actual conditions of the land, increasing the use of biological pesticide, promoting the use of organic agricultural film and recycling of waste agricultural film.

Third, the government should strengthen the supervision work. Lack of professional training and strict supervision acted as a block to the progress in low-carbon agriculture. Hence the government is supposed to propaganda the low-carbon concepts, raise awareness of agricultural material conservation and emission reduction among the farmers.

\section{Acknowledgments}

We are very grateful for the financial support provided by the Research Project of Humanities and Social Sciences in Jiangxi's Universities (Grant No. GL19225) and Chinese National Science Foundation (Grant No. 71473113).

\section{References}

1. J.S. Min, H. Hu, Estimation of greenhouse gas emissions from agricultural production in China, CJPRE, 22(07), 21-27 (2012) (in Chinese)

2. Y.F. Han, L. Zhang, Study on factorization of agricultural carbon emissions change in ChinaLMDI Decomposition Method based on energy Consumption and Trade, CER, 04, 47-52 (2013) (in Chinese)

3. B. Li, J.B. Zhang, H.P. Li, An empirical study on agricultural carbon emissions and economic development in China, JALRE, 25(12), 8-13 (2011) (in Chinese)

4. L. Cao, Y. Wang, S.J. Lei, Research on the spatiotemporal characteristics and decoupling elasticity of agricultural carbon emissions in Shandong Province, JAAS, 48(17), 250-256 (2020) (in Chinese)

5. H.P. Duan, Y. Zhang, J.B. Zhao, X.M. Bian, Carbon footprint analysis of farmland ecosystem in China, JSWC, 25(05), 203-208 (2011) (in Chinese)

6. F.L. Wu, L. LI, H.L. Zhang, F. Chen, Effects of conservation tillage on net carbon flux from farmland ecosystems, CJE, 26(12), 2035-2039 (2007) (in Chinese)

7. Y. Wang, Y. Zhou, L. Zhu, F. Zhang, Y.C. Zhang, Influencing factors and decoupling elasticity of China's transportation carbon emissions, E, 11(5), 1157 (2018) 